containing the nuclear structures and an outer segment containing about 1000 discs holding the pigment rhodopsin and lying within the cell membrane like a single stack of dinner plates; the apex of the outer segment of the rod is closely related to a pigment epithelial cell. The discs, with their pigment, are constantly formed from the cell membrane at the base of the outer segment. Autoradiographical studies ${ }^{1}$ have shown that these discs traverse the outer segment of the rod to be phagocytosed by the pigment epithelial cell at its apex. This process is influenced by the retinal illumination and has a circadian rhythm, more discs being phagocytosed in the light. ${ }^{2}$ In the pigment epithelial cell the discs are metabolised and the products recycled to the photoreceptors or removed through Bruch's membrane to the choriocapillaris. The phagocytic capacity of the pigment epithelial cell is astonishing. In the rhesus monkey the rod outer segment is renewed in eight or nine days. A pigment epithelial cell supports 24-45 rods, each of which is producing new discs at the rate of one every 16-18 minutes. Each pigment epithelial cell therefore phagocytoses between 2000 and 4000 discs a day, ${ }^{3}$ and this rate may be substantially increased if the rod is damaged. The point of failure in this intricate process in retinitis pigmentosa is unknown, but elegant chimera studies in the RCS rat (a species with an inherited retinal dystrophy) have shown that the defect in this animal lies in the pigment epithelial cell. ${ }^{4}$ Studies in human retinitis pigmentosa indicate that the rod outer segments are shorter than normal and that, at least in some types, the defect may lie within the rod; this is supported by the scanty pathological information that is available. ${ }^{6}$

About half the patients in south-east England with retinitis pigmentosa have a definite family history, ${ }^{7}$ and patterns of autosomal recessive, $\mathrm{X}$-linked, and dominant inheritance are all seen. While the $\mathrm{X}$-linked form is probably pure there may be several types of recessive or dominant diseases, each caused by a different genetic defect, so that analogies between individual families might not be valid. An accurate family history is most important, since different types of retinitis pigmentosa have different visual prognoses. Recessive and X-linked forms tend to be more severe, patients losing vision in early adulthood, while patients with a dominant pattern of inheritance may retain tiny fields and good acuities throughout their working lives, and some affected people may be apparently symptom free. Women carriers of the X-linked variety may be affected later in life, which may cause confusion in interpreting pedigrees. Accurate diagnosis of the pattern of inheritance is especially important in X-linked retinitis pigmentosa, which can be controlled by determination of fetal sex and termination of pregnancy.

The many patients without an apparent genetic background represent a heterogenous group of those without adequate family history, new mutations, and possibly a few in whom the disease is due to environmental causes such as syphilis or trauma. Retinitis pigmentosa may be associated with systemic diseases such as abeta-lipoproteinaemia, Refsum's disease, Batten's disease, chronic external ophthalmoplegia, or the Laurence-Moon-Biedl syndrome, but these represent only a minute fraction of the total. These conditions are usually associated with obvious evidence of a neuropathy, deafness, dementia, or myopathy. The neuropathy of Refsum's disease may be subtle, but the diagnosis should not be overlooked since an effective treatment is now available which prevents neurological progression, ${ }^{8}$ though visual recovery is unlikely because of the established retinal damage.

No treatment has been shown to restore or prolong vision in any type of human retinitis pigmentosa, but nevertheless much can be done to help affected patients. Spectacles and low vision aids help them make the most of their remaining sight, and accurate genetic diagnosis provides a visual prognosis and helps direct young patients towards suitable types of employment. Cataracts tend to occur, especially in X-linked disease, and may require surgery. The Retinitis Pigmentosa Society provides help and information for patients and is active in raising funds for research. Current research on human retinitis pigmentosa is hampered by lack of good pathological specimens-reports from all parts of the world include adequate histological examination on only three or four elderly eyes. This lack of material might be remedied if techniques of chorioretinal biopsy became established, ${ }^{9}$ but at present these offer too many risks to be acceptable. Light is toxic to the retina of the RCS rat, ${ }^{10}$ and indeed there has been some anxiety recently about damage to the retina in normal eyes from the levels of illumination achieved with modern ophthalmic equipment, ${ }^{11}$ and in time patients may be advised to avoid excessive illumination. In the meantime there is some merit in patients with retinitis pigmentosa being managed by ophthalmologists with a special interest in the disease.

Young RW, Bok D. Participation of the retinal pigment epithelium in the rod outer segment renewal process. F Cell Biol 1969;42:392-403.

La Vail MM. Rod outer segment disc shedding in relation to cyclic lighting. Exp Eye Res 1976;23:277-80.

3 Young RW. The renewal of rod and cone outer segments in the rhesus monkey. F Cell Biol 1971;49:303-18.

* Mullen RJ, La Vail MM. Inherited retinal dystrophy: primary defect in pigment epithelium determined with experimental rat chimeras. Science 1976;192:799-801.

${ }^{5}$ Ripps H, Brin KP, Weale RA. Rhodopsin and visual threshold in retinitis pigmentosa. Invest Ophthalmol Vis $S c i$ 1978;17:735-45.

Szamier RB, Berson EL. Retinal ultrastructure in advanced retinitis pigmentosa. Invest Ophthalmol Vis Sci 1977;16:947-62.

Bird AC. X-linked retinitis pigmentosa. Br f Ophthalmol 1975;59:177-99.

Gibberd FB, Billimoria JD, Page NGR, Retsas S. Heredopathia atactica polyneuritiformis (Refsum's disease) treated by diet and plasmaexchange. Lancet 1979 ; $1: 575-8$.

${ }^{9}$ Constable IJ. Problems of chorioretinal biopsy. F R Soc Med 1980;73: 408-12.

10 La Vail MM, Battelle BA. Influence of eye pigmentation and light deprivation on inherited retinal dystrophy in the rat. Exp Eye Res 1975; $21: 167-92$.

${ }^{11}$ Calkins JL, Hochheimer BF. Retinal light exposure from ophthalmoscopes, slit lamps and overhead surgical lamps. An analysis of potential hazards. Invest Ophthalmol Vis Sci 1980;19:1009-15.

\section{Crises and interventions}

Can prompt intervention within the community in a crisis reduce admissions to mental hospitals and help people to cope with future problems? These questions were discussed at a recent conference on crisis intervention services organised by the National Association for Mental Health (MIND). Though definitions of crisis vary from emotional distress to fully fledged breakdown or family catastrophe, attempts at prevention form a common thread.

"Giving up one way of viewing the world and developing another," said Dr C Murray Parkes, is a useful concept in this preventive approach. With the right help a potential crisis may become a point of growth, but the help has to be now rather than next week and to be without a time limit. It is, however, essentially brief intervention concentrating on the here and now. Admission to mental hospital, which so often sidesteps the real problems, may then become a last resort. A further characteristic of many crisis services is that the client is seen in his home setting, when family therapy, by attending to the underlying problems, may help to save him from the role 
of scapegoat. In general, as Dr T M W Farewell emphasised, two distinct types of help are needed: one for the minority of "classic" crises triggered off by life events in a previously welladjusted person (the types of problems envisaged by crisis theory and practice ${ }^{1}$ ) and the other for the recurrent problems of those who struggle from crisis to crisis.

Crisis and emergency services may be organised in several ways. ${ }^{1}$ Some have an open-door policy but most "filter" their clients in one way or another; many operate 24 hours a day, but this is not always possible. In some services there is a blurring of roles among the different medical, social, and supporting staff. Most depend on multidisciplinary teams, whether they are hospital or community based. Napsbury Hospital, near St Albans, has a well-established example of a hospitalbased community service, ${ }^{2}$ in which two people out of the team of doctor, social worker, and community nurse visit the home in all cases referred by general practitioners and police before any patient is admitted to hospital - and many do not then need to be. Tower Hamlets for the past five years has provided community-based therapy in cases of "psychosocial crisis" referred by any agency. ${ }^{3}$ In many of these cases solutions rely less on drugs and formal psychiatry than on community support, such as groups to help with children. More specialised types of service include counselling the bereaved ${ }^{4}$ and others with particular needs, and "crisis" help provided for the mentally sick by a day therapeutic community or other day centre. More simply, much may be achieved by psychiatric social workers attached to general practitioners. The basic question in setting up an emergency service, it was suggested, is "What is going to be done that existing services do not do?"

What evidence is there that services of this kind are effective? Professor John Cooper was sceptical about evidence of prevention so far; in his WHO study he found "little to suggest that the original optimism about prevention and growth through experience had been justified"-if only because the clients are usually people with chronic disorders rather than those who need constructive help through a severe specific crisis. ${ }^{1}$ Preliminary statistics suggest that crisis services do reduce admissions to mental hospitals, but this may merely reflect a shifting of the burden from one service to another. Encouraging results, however, were reported from a controlled follow-up study at a family crisis centre in Denver, Colorado." Follow-up at six and 18 months showed that the crisis centre group had had half as much time off work as the controls, much less time in a mental hospital, and less drug treatment. Though there was no difference in personal or social functioning this group fared better in subsequent crises. The savings achieved by such a service, then, could be of several kinds-not only of resources but also of the stigma attached to mental illness and admission to hospital.

Clearly crisis services demand a huge commitment of both time and concerned care; are they not unrealistic in the present state of the health and social services? As Dr Farewell said, organisation of such services must start from things as they are, "using old bricks in a new way"-in other words, using committed and flexible staff for new approaches. The Tower Hamlets service, for example, has only two full-time members of staff, a community psychiatric nurse and an administrator (paid for by the King's Fund); others-employed by the hospital or the social services department-help voluntarily on a rota basis. Few workers are experienced in family therapy, and in Tower Hamlets some training sessions are given; but learning is mainly by "debriefing" and discussion of cases.

Among the possible pitfalls in these approaches are that they may antagonise other professionals-and also patients and their families-if they are applied without proper discussion and explanation, and without sensitivity to the feelings of those who are being helped. Furthermore, the very speed with which these cases are seen, decisions made, and action taken $\stackrel{\varrho}{c}$ may have its dangers through curtailing the time for observa- $\widehat{C}$ tion and for the evolution of symptoms or behaviour. ${ }^{1}$ On the $\overline{\bar{J}}$ other hand, much time is given to finding out what has led up to the crisis. All in all, there appears to be great potential here $₫$ for preventing and easing suffering, especially if the principle 2 summed up by Dr Murray Parkes is applied-"Understand with your emotions what the person's state is, and deal with $\stackrel{5}{9}$ him as a human being rather than a case of mental illness."

1 Cooper JE. Crisis admission units and emergency psychiatric services. Public health in Europe 11. Copenhagen: World Health Organisation Regional $\mathbb{\Phi}$ Office for Europe, 1979.

2 Ratna L. The practice of psychiatric crisis intervention. St Albans: Napsbury ڤ Hospital League of Friends, 1978 (at present out of print).

Knight L. Cushioning the crises. Community Care 1978;February:20.

4 Parkes CM. Bereavement counselling: does it work? Br Med f 1980;281: 3-6.

${ }^{5}$ Langsley DG, Machotka P, Flomenhaft K. Avoiding mental hospital $\frac{\widehat{\partial}}{\partial}$ admission: a follow-up study. Am f Psychiatry 1971;127:1391-4.

\section{Vibration syndrome again}

The vibration syndrome is not life-threatening and in most $\omega_{0}$ cases is only moderately disabling, but it should not be seen as a discomfort which has to be borne. Sadly, progress has been slow in solving the problems of the effects of vibration on the $\vec{\theta}$ human body. The main problems to which solutions are $\stackrel{\infty}{+}$ required are the effects of vibration on the hands and on the body as a whole. A less pressing question is whether peripheral nerve damage occurs ${ }^{12}$ and how important it is. The presence of cystic changes in limb bones is now considered by most observers to be unrelated to vibration. ${ }^{3}$

The best documented example of vibration white finger is $\overrightarrow{\overrightarrow{0}}$ now its occurrence in users of chain saws. The use of chain 3 saws intensified after their introduction to British forestry in the 1960s, and the morbidity was high: in one study $95 \%$ of operatives were affected compared with $6.6 \%$ in a control group. ${ }^{4}$ More recently the introduction of antivibration saws by the Forestry Commission has reduced the prevalence of $\dot{\sigma}$ vibration white finger and perhaps allowed some reversal of symptoms.

Over 30 years have passed since the Industrial Injuries Advisory Council was first asked to consider whether occupationally induced Raynaud's phenomenon should be made a $\widetilde{\sigma}$ prescribed industrial disease," and the council then rejected $\frac{D}{0}$ prescription on a majority view. In an interim report in 1970 the council again failed to reach a final decision, ${ }^{6}$ but its $\tilde{N}$ adoption of the terms "vibration syndrome" and "vibration $\mathrm{W}$ white finger" helped to clarify thought on the subject. The council recommended further inquiries, but in 1975 in its final majority report ${ }^{7}$ it was again unable to recommend $\stackrel{\mathscr{\Phi}}{\rightarrow}$ prescription.

The main stumbling block has been the difficulty of distinguishing between vibration white finger and non-occupational Raynaud's phenomenon, which may occur at times in as $\stackrel{\mathbb{Q}}{\Omega}$ many as one-tenth of the population. Since the Industrial Injuries Advisory Council first considered vibration injuries the 8 problem has been intensified by the widespread use of chain saws-a new and potent source of vibration. The Health and Safety Executive has recently published a review document on 